\title{
BMJ Open Is the Rule of Halves framework relevant for diabetes care in Copenhagen today? A register-based cross-sectional study
}

\author{
Astrid Ledgaard Holm, ${ }^{1}$ Gregers Stig Andersen, ${ }^{2}$ Marit E Jørgensen, ${ }^{2,3}$ \\ Finn Diderichsen ${ }^{1}$
}

To cite: Holm AL, Andersen GS, Jørgensen ME, et al. Is the Rule of Halves framework relevant for diabetes care in Copenhagen today? A register-based crosssectional study. BMJ Open 2018;8:e023211. doi:10.1136/ bmjopen-2018-023211

- Prepublication history for this paper is available online. To view these files please visit the journal online (http://dx.doi org/10.1136/bmjopen-2018023211).

Received 27 March 2018 Revised 25 July 2018 Accepted 21 September 2018

Check for updates

(c) Author(s) (or their employer(s)) 2018. Re-use permitted under CC BY-NC. No commercial re-use. See rights and permissions. Published by BMJ.

${ }^{1}$ Department of Public Health, University of Copenhagen, Copenhagen, Denmark ${ }^{2}$ Clinical Epidemiology Research Group, Steno Diabetes Center Copenhagen, Gentofte, Denmark ${ }^{3}$ National Institute of Public Health, Southern Denmark University, Odense, Denmark

Correspondence to Dr Finn Diderichsen fidi@sund.ku.dk

\section{ABSTRACT}

Objective The study aimed at analysing whether the 'Rule of Halves' framework applies for diabetes care in the Danish healthcare system with high levels of accessibility and equity. The Rule of Halves states that only one-half of people with a particular chronic condition are diagnosed; one-half of those diagnosed get treatment, and one-half of treated achieve desired therapeutic goals.

Design The analysis is cross sectional based on available surveys, register data and clinical databases covering the adult population in Copenhagen. We analysed five levels of prevention and care including behavioural risk factors and biomarkers, prevalence of diagnosed and undiagnosed diabetes as well as how many received care according to guidelines and achieved relevant outcomes.

Setting The study population is Copenhagen City with a population of 550000 with 21500 prevalent cases of diabetes. While the registers used cover the whole population, the surveys include 750 cases and the biobank data 365 cases.

Outcome measures Outcome measures are for each level of analysis: the prevalence of high-risk individuals, prevalence of undiagnosed and diagnosed diabetes, proportion receiving treatment and proportion achieving quality and treatment targets.

Results We found that the 'Rule of Halves' framework raises relevant questions on how diabetes care works in a specific population, but the actual proportions found in Copenhagen are far from halves. Our analyses showed that $74 \%$ are diagnosed and among those who are $90 \%$ are receiving care. $40 \%-60 \%$ have achieved target levels of treatment in terms of $\mathrm{HbA1c}$ level and lipid levels. $80 \%$ have received eye and foot examinations in the last 2 years. $11 \%$ have retinopathy and $25 \%$ have macrovascular complications.

Conclusion Copenhagen is doing much better than halves, when it comes to diagnosis and providing treatment, whereas the Rule of Halves still prevails when it comes to treatment targets. There is thus still room for improvement.

\section{INTRODUCTION}

In Denmark, the prevalence of registered type 2 diabetes was estimated to be $5.5 \%$ in $2011,{ }^{1}$ with an annual increase of $6 \%$ since
Strengths and limitations of this study

- Without a representative national health examination survey designed specific for performing a Rule of Halves analysis the combined use of postal surveys with self-reported data, register data, clinical databases and samples from biobanks was used. It means that estimates within each level of Rule of Halves analysis can be compared, but comparisons across levels, where different sources are used, may not be valid.

- The registers and clinical databases used have full population coverage but reporting on some quality indicators might be biased due to non-reporting from primary care general practitioners.

- The surveys and biobanks suffer from $50 \%$ to $60 \%$ non-participation rates, but comparisons with register data indicate low level of selection bias.

2000. In addition, a considerable number is undiagnosed. To counter the rise in diabetes incidence and its complications it is necessary to better understand which subgroups of the population are particularly vulnerable to diabetes. Further, among those who already have developed diabetes, it is important to identify patient groups not receiving the appropriate treatment. ${ }^{23}$ We applied a 'Rule of Halves' (RoH) approach to map out diabetes risk, diagnosis and treatment, and to identify vulnerable groups in the population of the City of Copenhagen in Denmark.

Despite the name, $\mathrm{RoH}$ is not a firm rule but rather a very context-dependent conceptual model, originally introduced in a survey of diabetes in New England in 1947. ${ }^{4}$ The RoH suggests that half the cases of a disease in a population stay undetected, half of those detected are untreated and half of those treated are not reaching treatment targets. The RoH was later found to apply for the British NHS in the 1980s for different chronic disorders including diabetes, hypertension 
and asthma. ${ }^{5}$ More recent studies from Europe indicate that ROH might still apply for hypertension in some areas $^{6}$ while Finland, after ambitious cardiovascular disease (CVD) programmes, has improved to something like a rule of thirds. ${ }^{7}$ Today, the RoH is mostly found to apply in middle-income countries such as India where several studies on diabetes and hypertension have been done. ${ }^{8-10}$ The empirical findings for diabetes seem here more often to be a rule of two-thirds. ${ }^{8}$ The international initiative 'Cities Changing Diabetes' aims at improving diabetes control in several cities of high/middle-income countries and both $\mathrm{RoH}$ analyses and vulnerability assessments are done to identify policy entry points and target groups for those efforts. ${ }^{11}$ This paper reports on the $\mathrm{RoH}$ analysis done for the City of Copenhagen, capital of Denmark.

What applied in the USA 70 years ago might not apply to today's public health systems in a fast-changing global environment at different stages of nutritional and epidemiological transition. Even if the RoH does apply for some population groups and in some countries, the prevailing health inequalities even in the Scandinavian welfare states make it relevant to identify subgroups of the population where there might be inequalities in the rate of diagnoses and treatment. It has, for example, recently been shown that survival after diagnosis of diabetes is $66 \%$ higher among high-income compared with low-income groups. ${ }^{12}$ Also, increasing focus on prevention and early detection not least within the area of diabetes has made it imperative to address people with disease and to include high-risk populations in the RoH model.

The primary aim of this study was to determine whether an $\mathrm{RoH}$ applies for type 2 diabetes in Copenhagen. Further, we wished to identify inequalities in the occurrence, treatment and outcomes of type 2 diabetes in order to contribute to a better understanding of the social distribution of diabetes, its causes and consequences in order to highlight inequalities that are not visible in the averages of the RoH model. The study might support health planning in Copenhagen City by identifying groups with unmet needs and test the more general question whether RoH applies for diabetes in a Nordic welfare state of today.

\section{METHODS}

\section{Data sources}

Since regular representative health examination surveys are not performed in Denmark, this RoH analysis was conducted based on existing quantitative data from four population and clinical registers, two waves of a repeated postal survey and one biobank on middle aged with health examinations.

The National Health Survey (NHS) is a repeated postal questionnaire survey conducted among a representative sample of citizens aged 16 or above. The Health Survey presents data on health, sickness and health behaviour. Data from the two waves of the survey conducted in 2010 and 2013 were analysed. A total of 95150 persons were invited in each wave and response rates were $52.3 \%$ and $43.5 \%$, respectively ${ }^{13} .{ }^{14}$ We used data from respondents living in the City of Copenhagen.

Copenhagen Ageing and Midlife Biobank (CAMB) is a Danish population-based cohort study, combining detailed life course information with measures of physiological functioning and health. ${ }^{15}$ All cohorts included participants from the Greater Copenhagen area, but not specifically from the City of Copenhagen, and all participants were middle aged between 49 and 63 years in 20092011. Of the 17937 invited participants, $40 \%$ completed a postal questionnaire and underwent a health examination including body mass index (BMI) and blood samples including HbAlc.

National medical registers. The National Patient Register (LPR) covers all admissions and outpatient treatments at public somatic hospitals for the entire Danish population, and includes information on diagnosis. ${ }^{16}$ The Register of Medicinal Product Statistics (LSR) contains information about sales of all prescribed medicinal products in Denmark. ${ }^{17}$ Data from the two registers are linked to demographic and socioeconomic data via Statistics Denmark. Data from the year 2011 were used for the analyses, and limited to residents in the City of Copenhagen aged 16 or older.

The Danish Adult Diabetes Database (DVDD) is a nationwide clinical quality database on diabetes treatment. Results of yearly clinical assessments of patients diagnosed with type 1 and type 2 diabetes are reported to DVDD from hospital outpatient clinics and general practitioners (GP).${ }^{18}$ It has been mandatory for hospital outpatient clinics to report since 2005, whereas data from GPs were reported gradually and voluntarily since 2006. All patients with diabetes over 17 years of age who have had contact with a hospital outpatient clinic or a GP are eligible for inclusion in the DVDD. Coverage of cases treated in the secondary sector of outpatient clinics is $97 \%{ }^{18}$ but still low from GPs. The coverage of clinical data of those included is better than $90 \% .{ }^{18}$ For the DVDD-based analyses in the present study, we defined 'the Capital area' of Copenhagen according to Statistics Denmark's definition, and therefore included patients with type 2 diabetes treated at GPs or outpatient clinics within the postal codes 1100-2920 and 3500. A total of 25315 persons with type 2 diabetes treated at clinics or GPs in the Capital area of Copenhagen were included in the analyses. DVDD was linked with the National Patient Register and the Cause of Death Register for identification of complications. DVDD includes demographic data on age, sex and country of birth but no socioeconomic or educational status data. Table 1 gives an overview of the variables included from each of the four data sources.

Patient and public involvement. The study has not involved patients or the public but the results have been used by the health administration of the City of Copenhagen for planning a better diabetes prevention and care. 
Table 1 Physiological, behavioural, demographic and socioeconomic factors included in the analyses

\begin{tabular}{|c|c|c|c|c|}
\hline & $\begin{array}{l}\text { Health } \\
\text { Survey }\end{array}$ & $\begin{array}{l}\text { Register } \\
\text { data }\end{array}$ & DVDD & CAMB \\
\hline \multicolumn{5}{|c|}{ Physiological and behavioural risk factors } \\
\hline $\begin{array}{l}\text { BMI (calculated } \\
\text { from weight and } \\
\text { height) }\end{array}$ & $\mathrm{x}^{*}$ & & $x \dagger$ & $x \dagger$ \\
\hline Physical activity & $x^{*}$ & & & $x^{*}$ \\
\hline Smoking status & $x^{*}$ & & $x^{*}$ & $x^{*}$ \\
\hline Blood pressure & $x^{*} \ddagger$ & & $x \dagger$ & $x \dagger$ \\
\hline Cholesterol & & & $x \dagger$ & $x \dagger$ \\
\hline Diabetes diagnosis & $\mathrm{x}^{*}$ & $x \S$ & $x \dagger$ & $x^{*}$ \\
\hline \multicolumn{5}{|c|}{ Demographic and socioeconomic factors } \\
\hline Age & $x \S$ & $\mathrm{x}$ & $x \S$ & $x \S$ \\
\hline Sex & $x \S$ & $x$ & $x \S$ & $x \S$ \\
\hline Ethnicity & $x \S$ & $x$ & $x \S$ & \\
\hline Education & $x \S \bigoplus$ & $x ף$ & & $x^{*}$ \\
\hline Employment status & $x \S$ & $\mathrm{x}$ & & $x^{*}$ \\
\hline \multicolumn{5}{|l|}{ Screening service } \\
\hline $\begin{array}{l}\text { Date of last eye } \\
\text { examination }\end{array}$ & & & $x$ & \\
\hline $\begin{array}{l}\text { Date of last foot } \\
\text { examination }\end{array}$ & & & $\mathrm{x}$ & \\
\hline
\end{tabular}

*Self-reported.

†Measured values.

fln the Health Profile, participants only report whether or not they

have high blood pressure.

$\S$ Based on linkage with register data.

IEducational level was grouped into: low education defined as primary or secondary school, semiskilled or skilled worker; medium education defined as up to 4 years' theoretical education; and high education defined as more than 4 years' theoretical education. BMI, body mass index; CAMB, Copenhagen Aging and Midlife Biobank; DVDD, Danish Adult Diabetes Database.

\section{Analyses}

Five analytical levels (0-4) in the RoH analysis for diabetes in Copenhagen were assessed through the following analyses:

Level 0: The population at high risk of developing diabetes was assessed through prevalence (among those without diabetes) of risk factors, high diabetes risk score (defined by an adapted version of the Diabetes Risk Score based on age, sex, BMI, hypertension and physical activity ${ }^{19}$ ) or high-risk HbAlc level between 42 and $47 \mathrm{mmol} / \mathrm{mol}$ $(6.0 \%-6.5 \%),{ }^{20}$ using data from the National Health Survey (NHS) and the CAMB study.

Level 1: The population with diagnosed and undiagnosed diabetes was assessed using data from the NHP and CAMB study, estimating both the total population with diabetes (self-reported or $\mathrm{HbA} 1 \mathrm{c} \geq 48 \mathrm{mmol} / \mathrm{mol}(6.5 \%))^{16}$ and the proportion with undiagnosed diabetes (defined as no self-reported diabetes but an HbA1c level of $\geq 48 \mathrm{mmol} /$ mol).
Level 2: The proportion of patients with type 2 diabetes receiving diabetes care was described using register data. Diabetes was defined as admission with primary diagnosis E10-E14 (International Classification of Diseases 10th Revision, ICD-10) in LPR or as having filled a prescription for drugs with Anatomical Therapeutic Chemical code A10 in LSR. To assess diabetes-specific care, the extent to which patients in the DVDD database received examinations for complications and had clinical markers assessed according to national guidelines was analysed. The Danish national guidelines suggest eye examinations every second year, foot examinations every year and yearly assessments of HbAlc, lipids and blood pressure. ${ }^{21}$

Level 3: The population achieving treatment targets was analysed using DVDD data and defined as those having well-regulated HbAlc levels $(<53 \mathrm{mmol} / \mathrm{mol})$, blood pressure $(<130 / 80 \mathrm{~mm} \mathrm{Hg})$ and lipid levels (low-density lipoprotein (LDL) cholesterol $<2.5 \mathrm{mmol} / \mathrm{L}$ in patients without existing complications, and $<1.8 \mathrm{mmol} / \mathrm{L}$ for patients with existing complications). Dyslipidaemia, hypertension and elevated HbAlc levels are known risk factors for development of diabetes complications, and the above cut-off levels for blood pressure, LDL cholesterol and Hbalc levels are defined in national guidelines for treatment of type 2 diabetes. ${ }^{21}$ Further, based on data from the CAMB study the proportion achieving treatment targets was estimated as those with self-reported diabetes that had measured $\mathrm{HbA1c}<53 \mathrm{mmol} / \mathrm{mol}$.

Level 4: The population achieving desired treatment outcomes was defined as those without microvascular or macrovascular complications. The part of the population with type 2 diabetes that experienced macrovascular complications was assessed with data from the LPR register (admission with ischaemic heart disease (ICD-10: I20-I25), peripheral arterial disease (ICD-10: I70, E11.5, E13.5, E14.5) or cerebrovascular disease (ICD-10: I60-I69, G45)), the Health Profile (self-reported myocardial infarction, angina pectoris or stroke) and DVDD (ischaemic heart disease (ICD-10: I20-I25); peripheral artery disease (ICD10: I70-I71, I74-I75, I73.9); heart failure (ICD-10: I50I51, I11-I13); stroke (ICD-10: I63-I66, I69); amputations (ICD-10: Z89.4-Z89.7); and other CVD codes (ICD-10: E10.6, E11.6, E13.6, E14.6)). Microvascular complications were defined as occurrence of severe retinopathy (ICD-10: H33-H35, H43); diabetic kidney disease (ICD10: E10.2, E11.2, E13.2, E14.2, DN18.0, DN18.8, DN18.9, Z49.2, Z94.0, Z99.2); and neuropathy (ICD-10: E104, E114, E134, E144, DD62-63), and assessed based on the DVDD database.

To assess the distribution of diabetes and possible inequalities in diabetes occurrence and treatment, a list of physiological and behavioural risk factors, demographic and socioeconomic variables and information regarding health prevention were included in the analyses.

For level 0 to level 3 in the $\mathrm{RoH}$ analysis, proportions were calculated to characterise the overall population prevalence of diabetes outcomes. To determine the importance of different demographic, clinical and 
socioeconomic factors, the descriptive measures were stratified and multivariate logistic regression analyses were performed with diabetes outcomes as the dependent variable. In level 4 , differences in crude incidence rates based on incident events and person-years at risk were used to calculate the incidence of microvascular and macrovascular complications, and Cox regression models with adjustment for covariates were used to compare differences in incident complications across subgroups.

Analyses were performed using SAS for Windows (V.9.3) or Stata/IC V.12.1 for Windows. Survey analysis techniques were applied for the analyses of the NHS data weighted for non-response using a population weight calculated by Statistics Denmark. ${ }^{22}$

\section{RESULTS}

\section{Level 0: population at risk}

The prevalence of type 2 diabetes risk factors and pre-diabetes across demographic and socioeconomic groups is shown in table 2. Overall, $6.6 \%$ of the CAMB population have HbAlc levels considered to be a high risk for developing diabetes and $12.7 \%$ of the population in NHP have a high diabetes risk score. For the three risk factors examined, the results show that $10 \%-15 \%$ of the population are obese, $15 \%-30 \%$ are physically inactive and 23\%-28\% smoke. With regard to demographic and socioeconomic factors, higher prevalence of diabetes risk factors is found among males, people with higher age, lower education and no employment. For ethnicity, the pattern is less clear; people with a non-western background have higher rates of obesity and physical inactivity, but more people with a western background smoke. Finally, those living with others or having children living at home have lower prevalence of diabetes risk factors and lower diabetes risk score. The results of the regression analyses also show that especially low education and not being employed are related to a higher diabetes risk score and pre-diabetic HbAlc level (table 2). Analyses of preventive services based on NHP data showed that $35 \%-45 \%$ of the population with high risk of diabetes received information regarding prevention and 9\%-13\% accepted offers to participate in preventive interventions, compared with $13 \%-18 \%$ and $2 \%-4 \%$ of those with low diabetes risk (results not shown).

\section{Level 1: population with diagnosed or undiagnosed diabetes}

There are clear socioeconomic differences in the self-reported prevalence of diabetes (see table 3). Figures from the NHS show a prevalence of $5.8 \%$ among low educated compared with $1.3 \%$ among high educated. Among the not employed the prevalence is $10.4 \%$. Based on CAMB data on middle aged, the overall prevalence of diabetes (self-reported or measured HbAlc of $\geq 48 \mathrm{mmol} / \mathrm{mol}$ ) was $4.2 \%$. From that data we can further estimate a proportion of undiagnosed diabetes of $1.1 \%$ defined as the proportion with HbAlc of $\geq 48 \mathrm{mmol} / \mathrm{mol}$ that did not report diabetes in the interview. This means that $26 \%(1.1 / 4.2)$ out of the total of $4.2 \%$ are not diagnosed. Further, if the proportion of diagnosed diabetes from CAMB data (74\%) is assumed to apply to all age groups of the adult population and is combined with the self-reported diabetes prevalence from NHS $(3.8 \%)$ which comprises a broader age range, then the diabetes prevalence in Copenhagen would be $3.8 / 0.74=5.1 \%$.

\section{Level 2: population receiving diabetes care}

Among the 25316 people in the Capital area with type 2 diabetes in DVDD, 13027 people had minimum 2years' follow-up time and a valid date of eye examination. Of these, more than $80 \%$ had an eye examination within 2 years of the last clinical examination. There were no significant differences in the odds for having eye screening across sex, age groups or region of origin (table 4). Of those people with minimum 1 year follow-up time and a valid date of last foot examination, $81.4 \%$ had a foot examination within a year of the last clinical examination. Women and older age groups were more likely to receive yearly foot examination, whereas migrants from the Middle East and North Africa were less likely compared with Danish born. Among those with minimum 1 year follow-up time and a valid date of last HbAlc assessment, more than $90 \%$ had an HbA1c assessment within the last year of last clinical examination. A total of 12412 patients were included in the analyses of blood pressure assessment and almost $90 \%$ were treated according to national guidelines. ${ }^{21}$ Young people and migrants from South and North America and Oceania were less likely to have blood pressure assessment, but still $>85 \%$ of the patients in these subgroups had an annual assessment.

Lipidswere assessed in close to $80 \%$ of patients according to national guidelines. Again, young people and migrants from Europe were less likely to receive assessment.

\section{Level 3: population achieving treatment targets}

Based on data from the DVDD database, the proportion of patients with type 2 diabetes whose clinical values were within the national treatment targets in 2012 is shown in table 5. Overall, around $55 \%$ of the patients with a valid measurement had an HbAlc level within the national treatment target. This was the case for around $60 \%$ for LDL cholesterol, but only close to $40 \%$ for blood pressure. Adjusted models showed that men, young and middle-aged people and migrants were less likely to be within the national treatment target for HbA1C, compared with women, older people and native Danish born. For LDL cholesterol, there was a similar pattern, except for men who were more likely to be within the treatment target. For blood pressure, men were less likely to be within treatment target, whereas migrants and older age groups were more likely to be within treatment target compared with their respective reference groups.

\section{Level 4: population achieving desired outcomes}

In total, $40.3 \%$ of the people with type 2 diabetes in the Capital area who were alive and followed in DVDD as 


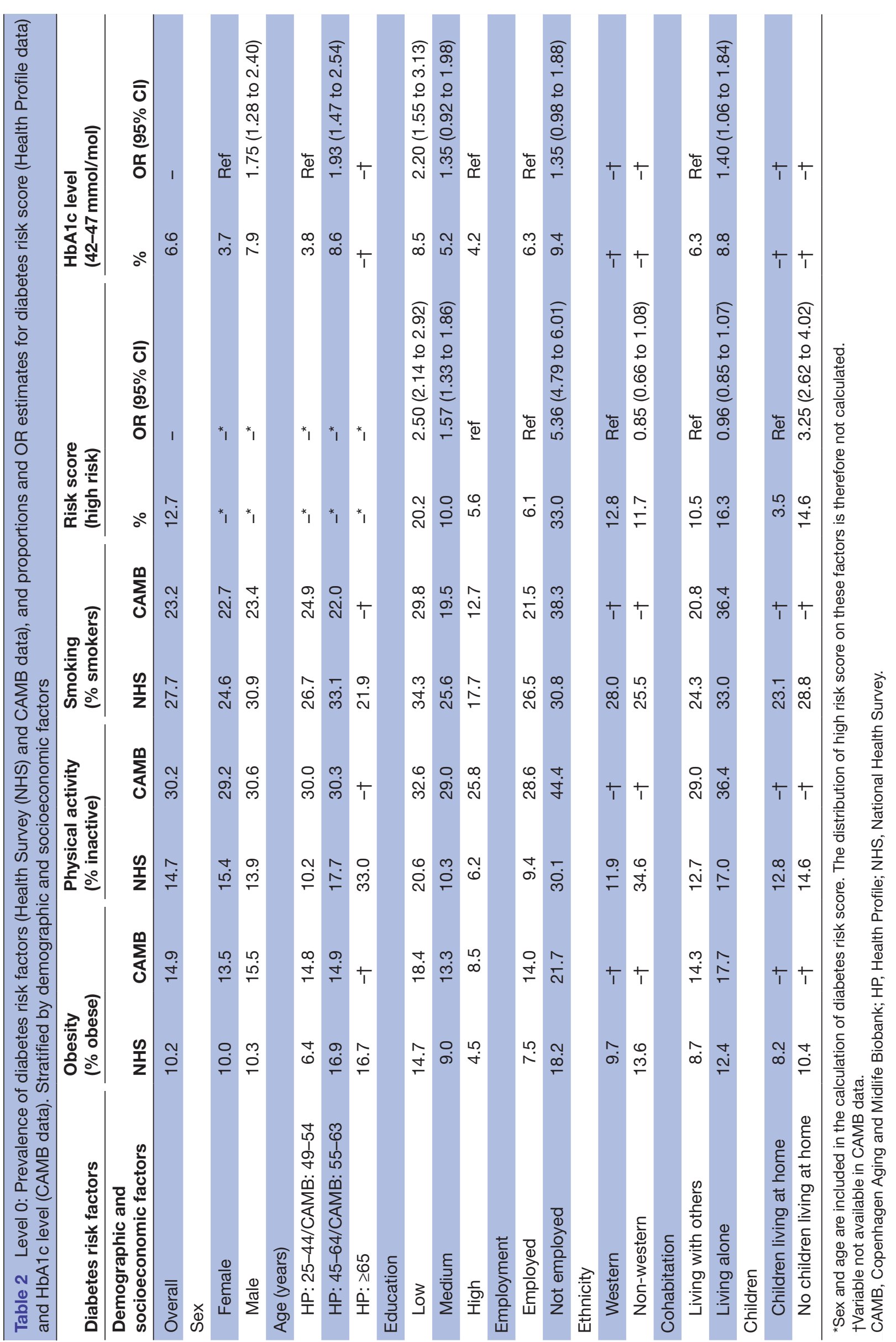


Table 3 Level 1: Proportions (\%) of self-reported, diagnosed and undiagnosed diabetes

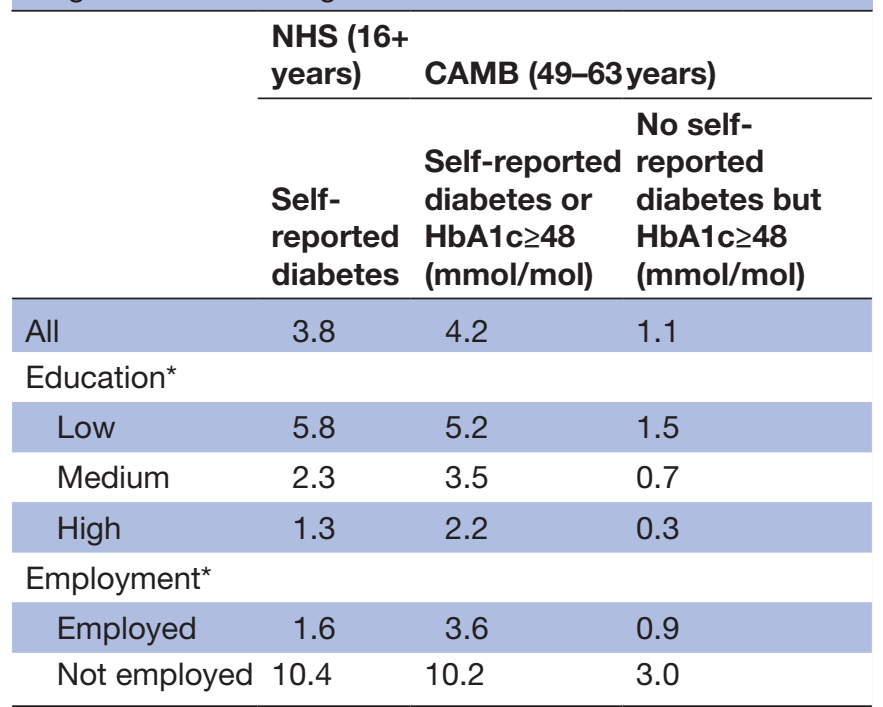

*The differences across educational level and employment are all significant, $\mathrm{p}<0.01$.

CAMB, Copenhagen Aging and Midlife Biobank; NHS, National Health Survey.

of 31 December 2012 had some type of complication. The prevalence of any complications among patients within treatment targets in 2012 was $30.3 \%$ for HbAlc, $42.6 \%$ for LDL cholesterol and $41.6 \%$ for blood pressure (results not shown). Based on these results and the overall prevalence of any complications among people with type 2 diabetes in the Capital area, approximately $60 \%$ of the people within treatment targets were without complications.

Based on register and survey data, respectively $11.4 \%$ and $24.8 \%$ of the population with diabetes had macrovascular disorders. The risk of macrovascular complications increased with age and was higher among males and those with no employment (results not shown). Based on data from DVDD, 28.5\% of the population in the Capital area had a diagnosis of CVD at some point following their diabetes diagnosis. The overall incidence rate for CVD in patients with type 2 diabetes was 57.4 per 1000 personyears in the Capital area, and with marked differences between sex and age groups (table 6). An estimated 11.3\% had a retinopathy and the overall incidence rate of retinopathy was 16.5 per 1000 person-years. Migrants from the Middle East and North Africa, and older people had a higher risk of developing severe retinopathy compared with native-born Danes and middle aged, respectively. For diabetic kidney disease, $18.3 \%$ had a diagnosis and the incidence rate was 18.5 per 1000 person-years. Men, older people and migrants from Europe were at increased risk of developing diabetic kidney disease compared with reference groups. Finally, $18.2 \%$ had a neuropathy diagnosis following their diabetes diagnosis, and the overall incidence rate was 17.7 per 1000 person-years. The stratified and adjusted analyses showed significantly higher rates among men and age was also a risk factor.

\section{DISCUSSION}

The results of our analyses show that the RoH levels do not generally apply for diabetes in Copenhagen; on most levels Copenhagen is doing better than simple halves. Overall, the results indicate that $10 \%$ of the population are at high risk of developing diabetes and $4.2 \%-5.1 \%$ have diabetes including the $1.1 \%$ we found to be undiagnosed cases. That is a slightly lower prevalence than we mentioned above for Denmark, ${ }^{1}$ but Copenhagen has both a younger and more well-educated population which might explain the difference. Three-quarters of the diabetes population were diagnosed. Preliminary findings from other Danish population-based samples have found similar levels with approximately one-third of cases undiagnosed..$^{23}$ Around $80 \%-90 \%$ of the patients diagnosed with diabetes received complications screening and clinical assessments according to national guidelines, and between $40 \%$ and $60 \%$ achieved treatment targets for HbAlc, cholesterol and blood pressure.

Our results show that there are major demographic and socioeconomic differences in the prevalence of risk factors, and occurrence and treatment of diabetes. High risk of diabetes was especially prevalent among those with low education and no employment. The latter is partly because they might be out of work due to their diabetes and complications. Obesity and physical inactivity were more prevalent among people with non-western background, whereas this was not the case for smoking. No socioeconomic data were available for the clinical data concerning the quality of treatment and prevalence of complications. With regard to ethnic differences, we found that men and migrants form the Middle East and Africa were less likely to receive foot examinations or have well-regulated HbA1c, and that some migrant groups scored high on microvascular complications, but the ethnic differences were often not large enough to be verified. The DVDD study does not include data on patient's socioeconomic position, but recent studies from Denmark have shown clear socioeconomic inequalities in diabetes care utilisation, ${ }^{24}$ regulation, ${ }^{25}$ complications and survival. ${ }^{12}$

The RoH concept includes both a framework for analysing proportions diagnosed, treated and achieving treatment targets and a rule about that this proportion usually will be halves. While we find the framework useful, the Rule of Halves clearly does not apply for diabetes in Copenhagen. Studies on both diabetes and hypertension have shown that the actual proportions are very context dependent and sensitive to differences in policies that influence coverage and quality. ${ }^{7-10}$ The large inequalities found for diabetes occurrence and consequences in an otherwise comparatively equal welfare state show the relevance of examining the above-mentioned proportions in different groups.

Our study is the first to examine diabetes in an urban, European contemporary setting, using the $\mathrm{RoH}$ as a guiding framework. Several high-quality data sources were used to describe five analytical levels, from being at risk to 


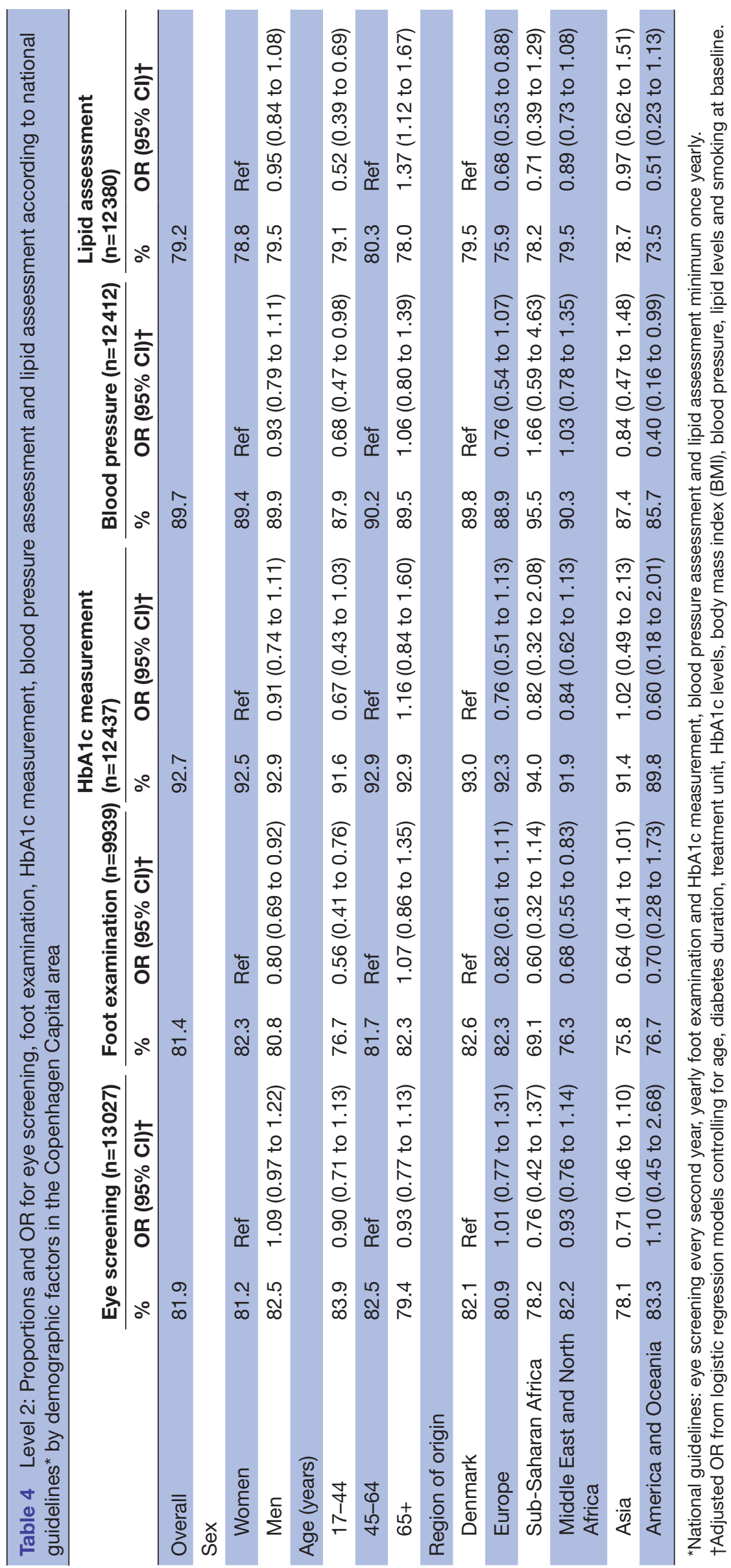


Table 5 Level 3: Proportion and OR for patients with type 2 diabetes in the Greater Copenhagen area to be within national treatment targets on $\mathrm{HbA1c}$, LDL cholesterol and blood pressure. Based on DVDD data

\section{Treatment targets}

\begin{tabular}{|c|c|c|c|c|c|c|}
\hline & \multicolumn{2}{|c|}{$\begin{array}{l}\text { HbA1c }<53 \mathrm{mmol} / \mathrm{mol} \\
(\mathrm{n}=14121)\end{array}$} & \multicolumn{2}{|c|}{$\begin{array}{l}\text { LDL cholesterol }<2.5 \mathrm{mmol} / \mathrm{L} \\
(\mathrm{n}=14171)\end{array}$} & \multicolumn{2}{|c|}{$\begin{array}{l}\text { Blood } \\
\text { pressure }<130 / 80 \mathrm{~mm} \mathrm{Hg} \\
(n=12511)\end{array}$} \\
\hline & $\%$ & OR $(95 \% \mathrm{Cl})$ & $\%$ & OR $(95 \% \mathrm{Cl})$ & $\%$ & OR (95\% Cl) \\
\hline Overall & 55.7 & & 60.6 & & 39.4 & \\
\hline \multicolumn{7}{|l|}{ Sex } \\
\hline Men & 54.9 & 0.91 (0.84 to 0.97) & 62.4 & 1.20 (1.12 to 1.28$)$ & 38.3 & 0.91 (0.85 to 0.98 ) \\
\hline Women & 56.8 & Ref & 58.1 & Ref & 40.7 & Ref \\
\hline \multicolumn{7}{|l|}{ Age (years) } \\
\hline $17-44$ & 47.1 & 0.95 (0.80 to 1.12$)$ & 45.6 & 0.70 (0.59 to 0.82$)$ & 42.7 & 1.13 (0.95 to 1.35$)$ \\
\hline $45-64$ & 50.5 & Ref & 56.6 & Ref & 38.6 & Ref \\
\hline $65+$ & 60.2 & 1.33 (1.23 to 1.42$)$ & 64.6 & 1.38 (1.29 to 1.49$)$ & 39.6 & 1.09 (1.01 to 1.18$)$ \\
\hline \multicolumn{7}{|l|}{ Region of origin } \\
\hline Denmark & 59.7 & Ref & 62.0 & Ref & 38.4 & Ref \\
\hline Europe & 48.8 & 0.65 (0.56 to 0.76$)$ & 57.0 & 0.84 (0.72 to 0.97$)$ & 37.2 & 0.95 (0.80 to 1.12$)$ \\
\hline Sub-Saharan Africa & 48.2 & 0.70 (0.48 to 1.02$)$ & 50.9 & 0.75 (0.51 to 1.10$)$ & 46.0 & 1.39 (0.93 to 2.06$)$ \\
\hline $\begin{array}{l}\text { Middle East and North } \\
\text { Africa }\end{array}$ & 36.5 & 0.42 (0.38 to 0.47$)$ & 56.1 & 0.90 (0.81 to 1.01$)$ & 45.1 & 1.33 (1.19 to 1.49$)$ \\
\hline Asia & 44.4 & 0.57 (0.45 to 0.72$)$ & 52.1 & 0.76 (0.60 to 0.95$)$ & 38.5 & $1.00(0.78$ to 1.29$)$ \\
\hline America and Oceania & 50.0 & 0.69 (0.40 to 1.18$)$ & 50.9 & 0.65 (0.38 to 1.12$)$ & 38.3 & 1.01 (0.56 to 1.82$)$ \\
\hline
\end{tabular}

DVDD, Danish Adult Diabetes Database; LDL, low-density lipoprotein.

development of complications. However, when drawing conclusions based on the results presented here, some methodological aspects of the analyses must be noted, as they might have affected the results. First and foremost, it is important to note that different data sources have been used for the different levels of the RoH analysis. Thus, the results from each level are not directly comparable, since the populations analysed were different in terms of background variables including age. It is possible that the prevalence of diagnosed and undiagnosed diabetes is underestimated due to the general under-reporting in surveys and the assumption that the proportion of diagnosed applies in all ages, when it is most likely higher among people aged above 64 , who were not included in the CAMB study.

Related to treatment targets, the estimate of well-regulated HbA1c based on CAMB data was higher than the estimate based on data from the DVDD database (level 4). This might be explained by the age group included in the CAMB study and/or the selection inherent in who participates in research examinations. Also, the exact geographical definition of Copenhagen differed between the two data. Further, we found a rather large difference in population prevalence of macrovascular complications based on data from the national registers versus the NHS. This is most likely due to many patients with mild disorders not being treated in the hospital system, but in primary care, and thus not included in the registers. The estimate from survey data was in agreement with estimates from the DVDD database, which include data from outpatient clinics and primary care units.

Some of the information from the NHS and CAMB was based on self-report, which might cause some degree of misclassification. The Capital Region has performed analysis of the coverage of self-reported disease in the Health Profile compared with data from registers. For diabetes, $73 \%$ of those detected through survey and registers together were identified when using survey data only. ${ }^{26}$ Data from the national Danish registers cover the entire population. However, not one register covers all health-related contacts: LPR includes only contacts with public hospitals, but private hospitals represent only a very small proportion of contacts. LSR includes all prescribed drugs including those made by doctors in primary care and private care. Primary care data are included in the DVDD, but since this reporting was not mandatory before 2013, the DVDD database does not contain complete information from primary care, and the vast majority of patients in DVDD are treated in hospital outpatient clinics. It is uncertain to what extent the GPs reporting to DVDD comprise a representative sample of GPs in Denmark. We might therefore underestimate the rates of complications if those GPs not reporting to DVDD have higher rates, but we expect that there are higher rates among those treated in hospitals. 


\begin{tabular}{|c|c|c|c|c|c|c|c|c|c|c|c|c|c|c|c|}
\hline 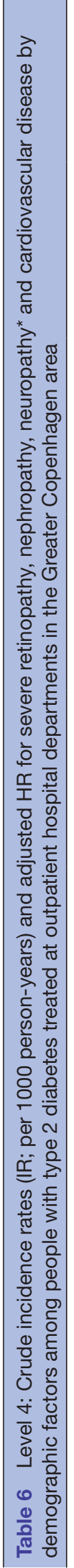 & 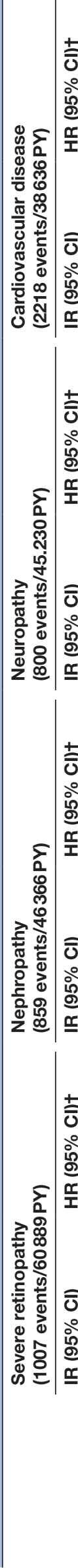 & 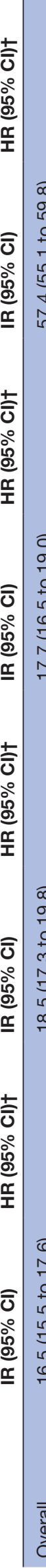 & 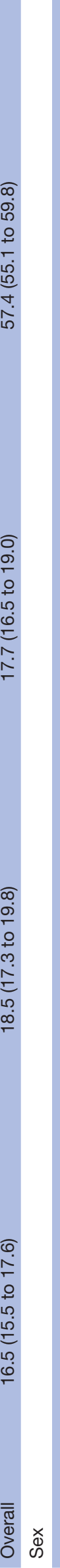 & 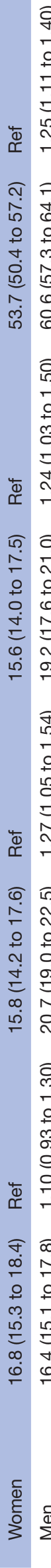 & 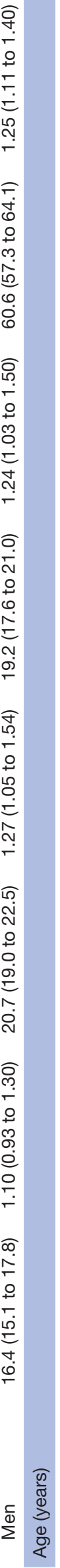 & 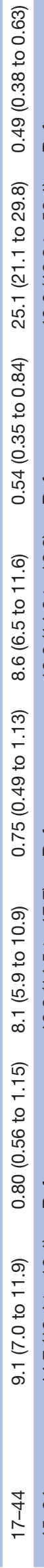 & 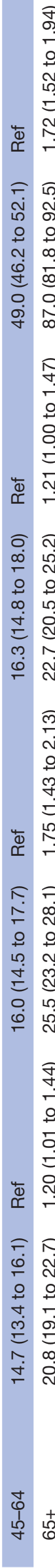 & $\begin{array}{l}. \frac{}{0} \\
\frac{\overline{0}}{0} \\
\overline{0} \\
+\frac{0}{0} \\
0\end{array}$ & 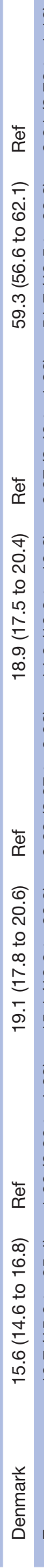 & 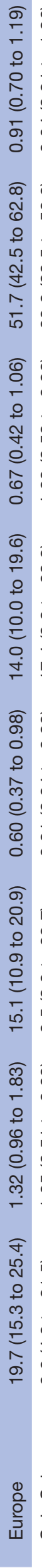 & 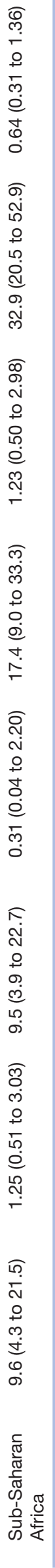 & 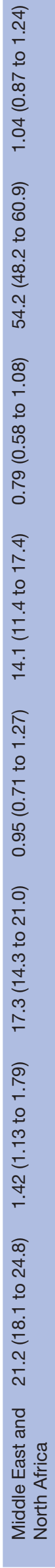 & 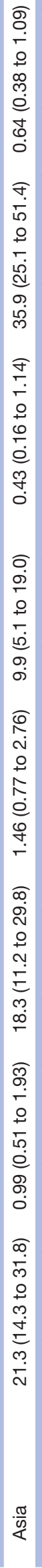 & 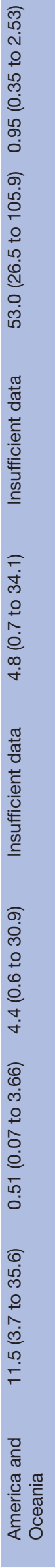 & 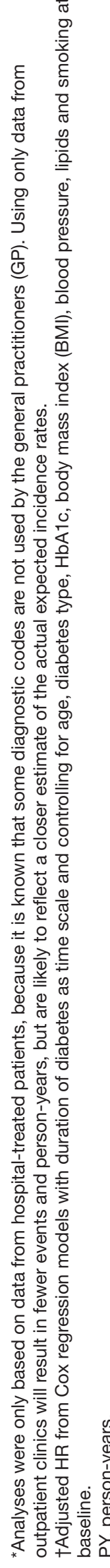 \\
\hline
\end{tabular}




\section{CONCLUSION}

The RoH model raises important questions about the proportions diagnosed, treated and reaching targets but any Rule of Halves is not supported in this study. Our analyses show that Copenhagen is doing better than halves, especially when it comes to diagnosing diabetes and providing treatment, whereas the proportions achieving treatment targets were closer to halves. Thus, there is still room for improvement.

Contributors ALH, FD and GSA conceptualised and designed the study. ALH and GSA have analysed registers and surveys and made the calculations. ALH made the first draft and FD, GSA and MEJ have contributed significantly to the revisions of the manuscript. All authors have approved the submission of this version of the manuscript.

Funding This study was conducted as part of the global mapping of urban diabetes challenges for the cities involved in the Cities Changing Diabetes programme initiated by Novo Nordisk. Novo Nordisk has partly financed the study.

Disclaimer Novo Nordisk has not been involved in the design, analyses or reporting of the study.

Competing interests None declared.

Patient consent Not required.

Ethics approval The ethics protection committee of Copenhagen has approved the Copenhagen Midlife Biobank used in this study (H-A-2008-12-6). The public registers and survey data used are not subject to ethical approval according to Danish law. All data materials are registered with the Danish data protection agency (Datatilsynet).

Provenance and peer review Not commissioned; externally peer reviewed.

Data sharing statement The study is based on linked public registers and surveys. Accessible from Statistics Denmark with special permissions.

Open access This is an open access article distributed in accordance with the Creative Commons Attribution Non Commercial (CC BY-NC 4.0) license, which permits others to distribute, remix, adapt, build upon this work non-commercially, and license their derivative works on different terms, provided the original work is properly cited, appropriate credit is given, any changes made indicated, and the use is non-commercial. See: http://creativecommons.org/licenses/by-nc/4.0/.

\section{REFERENCES}

1. Green A, Sortsø C, Jensen PB, et al. Incidence, morbidity, mortality, and prevalence of diabetes in Denmark, 2000-2011: results from the Diabetes Impact Study 2013. Clin Epidemiol 2015;7:430.

2. Brown AF, Ettner SL, Piette J, et al. Socioeconomic position and health among persons with diabetes mellitus: a conceptual framework and review of the literature. Epidemiol Rev 2004;26:63-77.

3. Houle J, Lauzier-Jobin F, Beaulieu MD, et al. Socioeconomic status and glycemic control in adult patients with type 2 diabetes: a mediation analysis. BMJ Open Diabetes Res Care 2016;4:e000184.

4. Wilkerson HLC, Krall LP. Diabetes in a New England town: a study of 3516 persons in Oxford, Mass. JAMA 1947;135:209-16.

5. Hart JT. Rule of halves: implications of increasing diagnosis and reducing dropout for future workload and prescribing costs in primary care. Br J Gen Pract 1992;42:116-9.
6. Weinehall L, Öhgren B, Persson M, et al. High remaining risk in poorly treated hypertension: the 'rule of halves' still exists. J Hypertens 2002;20:2081-8.

7. Nissinen A, Kastarinen M, Tuomilehto J. Community control of hypertension - experiences from Finland. J Human Hypertens 2004;16:553-6.

8. Kalra S, Saboo B, Sahay R, et al. The rule of two-thirds in diabetes epidemiology. Indian J Endocrinol Metab 2017;21:242-4.

9. Moser KA, Agrawal S, Davey Smith G, et al. Socio-demographic inequalities in the prevalence, diagnosis and management of hypertension in India: analysis of nationally-representative survey data. PLoS One 2014;9:e86043.

10. Irazola VE, Gutierrez L, Bloomfield GS, et al. Awareness, treatment, and control in selected communities of nine low- and middle income countries: results from the NHLBI/UHG network of centers of excellence for chronic diseases. Global Heart 2016;11:47-59.

11. Napier AD, Nolan JJ, Bagger M, et al. Study protocol for the Cities Changing Diabetes programme: a global mixed-methods approach. BMJ Open 2017;7:e015240.

12. Sorts $\varnothing \mathrm{C}$, Lauridsen J, Emneus M, et al. Social inequality in diabetes patients' morbidity patterns from diagnosis to death - A Danish register-based investigation. Scand J Public Health 2018;46:92-101.

13. Glostrup. Region Hovedstaden - Forskningscenter for Forebyggelse og Sundhed. Sundhedsprofil for Region og Kommuner 2010, 2011.

14. Glostrup. Region Hovedstaden - Forskningscenter for Forebyggelse og Sundhed. Sundhedprofil for Region Og Kommuner 2013, 2014.

15. Avlund K, Osler M, Mortensen EL, et al. Copenhagen Aging and Midlife Biobank (CAMB): an introduction. J Aging Health 2014;26:5-20.

16. Lynge E, Sandegaard JL, Rebolj M. The Danish National patient register. Scand J Public Health 2011;39(7 Suppl):30-3.

17. Sundhedsdatastyrelsen. Lægemiddelststatistikregisret. https://sund hedsdatastyrelsen.dk/da/registre-og-services/om-de-nationalesundhedsregistre/sygedomme-laegemidler-og-behandlinger/laeg emiddelstatistikregisteret

18. Jørgensen ME, Kristensen JK, Reventlov Husted G, et al. The Danish adult diabetes registry. Clin Epidemiol 2016;8:429-34.

19. Glümer C, Carstensen B, Sandbaek A, et al. A Danish diabetes risk score for targeted screening: the Inter99 study. Diabetes Care 2004;27:727-33.

20. Ackermann RT, Cheng YJ, Williamson DF, et al. Identifying adults at high risk for diabetes and cardiovascular disease using hemoglobin A1c. Am J Prev Med 2011;40:11-17.

21. Danish Society for endocrinology. Guidelines for type 2 diabetes, 2014 revision. http://www.endocrinology.dk/PDF/Farmakologiskbeh andlingDM2rev2014.pdf

22. Christensen Al, Ekholm O, Glümer C, et al. The Danish National Health Survey 2010. Study design and respondent characteristics. Scand J Public Health 2012;40:391-7.

23. Jørgensen ME, Carstensen B. Estimates of prediabetes and undiagnosed diabetes in Denmark. Paper presented at EASD; Lisbon, 2017. https://www.easd.org/virtualmeeting/home.html\#! resources/estimates-of-pre-diabetes-and-undiagnosed-diabetes-indenmark-a01228e8-3154-4e3f-b68f-15e788e360d9

24. Sortsø C, Lauridsen J, Emneus M, et al. Socioeconomic inequality of diabetes patients' health care utilization in Denmark. Health Econ Rev 2017;7:21.

25. Heltberg A, Andersen JS, Kragstrup J, et al. Social disparities in diabetes care: a general population study in Denmark. Scand J Prim Health Care 2017;35:54-63.

26. Hovedstaden R. Forskningscenter for forebyggelse og sundhed: hvordan opgøres kroniske sygdome, 2011. 